\title{
The Lifestyle in the Development of Ideological Policy
}

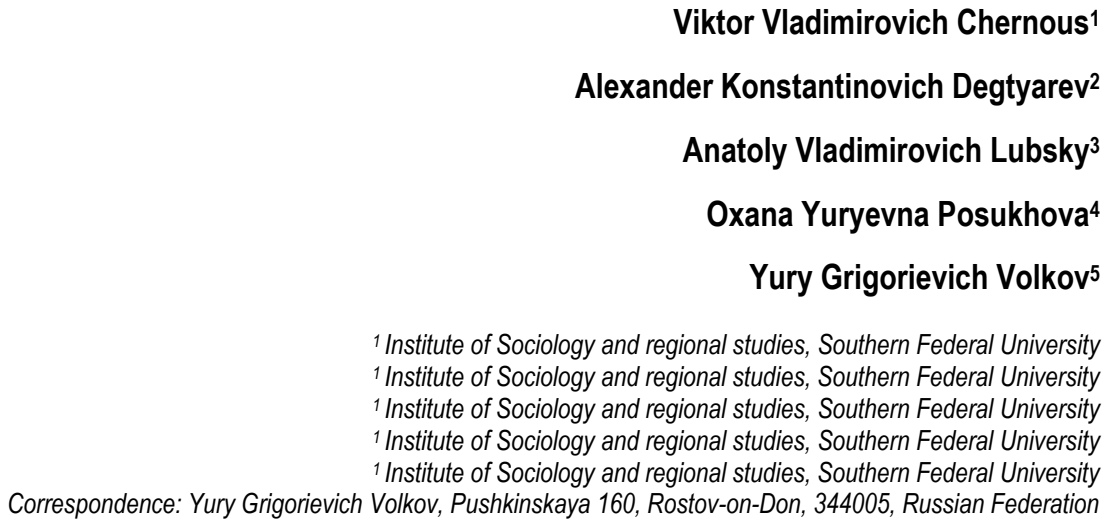

Doi:10.5901/mjss.2015.v6n5s4p503

\section{Abstract}

The goal of the article consists in understanding Islam as a lifestyle in Europe. The lifestyle is understood through creation and introduction of religious differences and determines the perception of Islam as different from the European values. This fact affects acceptance of the lifestyle as a legitimization of religious subjectness. The conclusion is made that the difficulty of integrating the Muslims into the European community consists in substitution of social issues for ethnocultural and ethnoreligious variety.

Keywords: lifestyle, Islam, perception of Islam, mass conscience, European community, ideological policy

\section{Introduction}

In the context of the tendency towards ethnic heterogeneity of the Western society, the issues of ethnicity have become the key ones in social, ideological, and value policy. The existing assimilation and integration models ceased to be adequate due to the fact that, despite the policy of tolerance, ethnical enclavisation, i.e., establishment of closed ethnical communities, is making unexpected influence, when conflicts arise in the form of clashes of lifestyles perceived as integral life forms with certain ethnical and enthnocultural differences. The studied issue, however, takes an unexpected turn: integration policy aiming at de-ethnicity of ever-arriving migrants resulted in substitution of ethnic perception, sense of belonging to the historical motherland through confessional self-conscience, in the context of which Islam is perceived and interpreted not as a tradition but rather as a lifestyle with total influence on practically all aspects of attitude to social reality.

\section{Literature Review}

The studied issue is researched through constructive approach dominating in the foreign social thought. Researching culture, identity, and "otherness" determines introduction of cultural differences into the scientific discussion and building of a diversity management model. That spurs interest to the conclusions of the constructionism researchers that the refusal of primordialisation as a risk of racialisation and ethnicity does not provide an opportunity to analyze the tendencies with all their contradictions and consequences. Thus, the works by J. Nuariel (2013), J. Fabbian (2013), A. Blum (2013) contain the conclusion that introduction of elements of encouragement of cultural differences results in transferring the weight from the social sphere to the cultural and moral and psychological spheres, where Islam satisfies a group's need in protection and development in the best way.

For that reason, D. Kandiyoti (2012), J. Haynes (2012), and W. Boender (2012) think that lifestyle is becoming an instrument of ethnic relations management insofar as possibilities of "Europeanization" go, accepting a lifestyle as a 
guidance concept in order for cultural differences to remain within the context of interethnic dialog.

\section{Methodology}

Taking into account that lifestyle in the context of this research can be differentiated as an analytical construction, the theoretical choice is determined, firstly, by accepting a communication and cognitive research paradigm which aims at determining the influence of Islam (interpreted as a lifestyle) at the level of interethnic relations. As the final goal is the integration of ethnical communities, the research also covers analysis of gaps which arise from substitutional influence of Islam as an identification matrix for the possibilities of integration which almost coincides with Europeanization.

\section{Results and Discussion}

Migration problem which grew dramatic due to desperate efforts of the European states to regulate the migration processes, that create strain in almost every sphere of social life, can be measured sociologically. Uncontrolled migration, firstly, comes from the Islamic countries (Libya, Tunisia, Algeria, Morocco, Syria); secondly, relates not only to the need to fund the programs for migrant support, but also to the inevitable effects of integration for the accepting community.

The policy of multiculturalness in the end of 90's of the XXth century practically meant that the European model of integration determined by the logic of studying, perceiving and accepting democratic values failed in the context of ethnoreligious enclavisation and parallel structures for regulation of education, management and everyday life in the Islamic diasporas. That "inconvenience" can be interpreted in a number of ways. The most superficial and popular is the position of radical deviation of Islam as a lifestyle which is hostile and alien to the European civilization.

Although radicalism is characteristic of the European new right-wing supporters that reproach the political elites in idleness and encouragement of Islam expansion, the election results of the parties speculating on migration, or rather anti-migration, policy show the growth of right-wing sentiments among representatives of different social layers. The moderate centrist approach to migrants integration is characterized by significant provisions about lack of options when developing a reasonable policy, building up a dialog with the representatives of moderate Islam who share secular values insofar as it is allowed by the ethnoreligious tradition.

According to the English researcher J. Delantiy, "it is often stated that Europe formed in the result of the selfdetermination process, in which Islam is "different" from the European "selfhood" (Delantiy, 2012). Based on the deviation of Islam openness to other cultural and political tendencies, a conclusion is made that the European community faced a poor choice: either to come to terms with Islam and accept it as an equivalent lifestyle (or at least recognize the right to the independent lifestyle of millions of Muslims), or to create blockers on Islam's way and introduce heavy regulation of Islam within the private sphere.

Promoting perception of Islam as a lifestyle, Delantiy associates non-acceptance of Islamic lifestyle with xenophobia, mystification, and stereotypization. One can say that the Islamic lifestyle is established in the context of Islam images in the European community, which, although having historical precedents, do not mean just the borderline between the European "I" and Islamic "other", but are determined by interdependence since the VIIth century, when the European border passed along the Pyrenees. Delantiy puts significant weight on overcoming historic complexes which build up mistrust between Europeanness and Islam.

It should be also mentioned that in the current "de-Christianized" Europe, Europeanness is associated with Christian tradition, which raises controversial implications concerning continuation of religious wars and crusades. Historical references cannot erase the boundaries between understanding Islam as a different lifestyle and attitude to Islam in the context of ethnoreligious tradition. For that reason, references to the European interest for the East (orientalism) are not considered a powerful argument in favor of the tradition of mutual understanding between Islam and Europeanness.

According to European researchers, orientalism reflects "decline" of the old Europe and, at the same time, is becoming the way of legitimizing a colonial mission aimed at creating claims about knowing "the nature of the East" (Said, 2003). Delantiy is concerned with the fact that the uncrossed boundary between Europeanness and Islam causes splits and contradictions in the European community, builds up mistrust among supporters of Islamic tradition to the policy of the authorities, and expresses in self-isolation in everyday life. However, defining orientalism as a tool for internal colonization emphasizes its influence on the current perception of Islam.

E. Said stated that perception of the Arabs and Islam is based on generalization of destructiveness which is said to be characteristic of the East (Said, 2003). That context calls for the "revealing" analysis of prejustices constituting not only "practical", but also discursive knowledge about Islam. Islam as a lifestyle is described as "different", but softening and 
liberalization of the estimation of Islam encourages self-isolation: discursive knowledge is applied in order to establish the boundaries of accepted influence in the Islamic communities and propose the model of accepted behavior of the Muslims in the alien sociocultural environment.

Preservation of the principles of orientalism relates (like with the external colonial rule) to segregation of society by religious parameters: not only legitimization and encouragement of certain rituals and rites, but also establishment of professional and household spheres conforming with the Islamic tradition. A lifestyle as a way of individual and collective activity preserves behavioral and cultural attitudes relating to the practices of "Islamic" migrants and schemes of Islam perception by "the intellectuals" and the masses. Lack of "social reason" must be the most acute problem in the established system of sociocultural communications, which expresses in introduction of tolerance imperative into the public discourse.

Externally, prohibition of "xenophobia" transforms the state of tension into the latent form which has a constant negative influence on the mass conscience. Defending their right to speak about difficulties of migrant integration, European right-wing supporters are, if not fair, but certainly right that "public muteness" stimulates readiness "to ignore each other". If orientalism is not expressed in the form of external regulators, this does not mean that "internal colonialism" is devoid of risk of spreading of ethnoreligious enclaves claiming for "internal sovereignty".

M. Gilsenan who takes an optimistic view of modernization potential of Islam, identifies a special feature which must be characteristic of supporters of the Islamic tradition in Europe: Supposing that Islam is a lifestyle different from Europeanness, then the tradition preserving historical memory becomes a behavioral and thinking principle, which determines the attitude towards sociocultural environment under transition to individual forms of the "dependent" capitalistic society (Gilsenan, 2008) . That statement means that, like in their historical motherland, migrants experience difficulties in adapting to the urban style of living, with blurred norms of traditionalism; moreover, status of a migrant makes them "marginals" due to the non-conformity to the liberal (democratic) values dominating in the society. Thus, Islam as a lifestyle is associated with collectivism, mutual help, cooperation based on common faith and neighbourship, in order to avoid the state of limitation and dependency characteristic of individualism.

Prohibition of xenophobia, coercion of the European community to tolerance and positively neutral attitude to differences alleviate the difficulties of social adaptation to immanent cultural differences. According to M. Vivierka, correlation between ethnicity of public life and fight against discrimination causes concerns, and not everything in it points at social progress (Demintseva, 2013). This is the phenomenon of interested groups, for which "variety" becomes the formula of political action. However, there is a connotation which directly relates to Islam. Islam indicates to which group a migrant belongs, even if it is not his or her personal choice.

It turns out that even an individual, who is not ready to accept Islam as his or her lifestyle, has to be tolerant to the norms and rules of Islam, in order to be included in the statistics of "variety". This casts doubt on the statement about constructed nature of identity, about the possibility to change it in the process of integration into the European community. The English professor D. Kandiyoti states that the current European understanding of pluralism has, in fact, dividual nature, and the right to differences, which introduces the imperative of identification and behavioral instability, is transformed, mostly, into the right to worship (Yilmaz, 2012). In his opinion, that is a relatively new tendency compared to the fact that in the 60-70's of the XXth century, migrants were still identified by their country of origin (Bangladeshi, Turks, Pakistani), rather than their religious affiliation.

One can assume that the identification trend is determined not only by blurring of national and state identities in today's Europe: the main factor is the procedure of "qualification" of migrants: migrants from Africa and the Caribbean are considered "black" in England. In the statistics of variety, a similar procedure is used for immigrants from the Middle East and Western Asia.

One can talk about encouragement of Islamisation in the official discourse: the imperative of multiculturalism is inevitably based on introduction of Islam as a social regulator. It obviously causes "concerns" of the European community about the growth of the number and influence of representatives of not just a different culture, but other worldview, behavior, and social perception. The Muslims in Europe are perceived as a religious community. While its homogenity and unity are heavily exaggerated, recognition of equality of all citizens in all aspects of life, including cultural and religious needs, contains social implications.

It is true that the initiatives about building new mosques or shops with "halal" foods, even not for religious and ethical reasons, have a direct influence on sociocultural environment and cause controversial reactions from those who are accustomed to other sociocultural landscape and refuse to accept the situation, when they cannot buy their standard set of products in a mini-market only due to respect of religious differences. The situation, that can be interpreted as a display of xenophobia, in reality is a defensive position of the mass conscience caused by the policy of "Islamisation" encouragement. One can agree with the fact that the European community must develop a formula of mutual 
understanding with Islamic migrants that welcome civil and social participation. The aspiration to make all those people a religious community is, however, questionable. In that situation, the rights of an individual cease to be an effective tool of collectivism: dominance is taken by collective values with an obvious need for self-organization within the influence on different spheres of life.

Another quite explicable phenomenon is the phenomenon of "cloning" of the organizations which stand for development and implementation of an independent Islamic policy, Islamic education, upbringing through providing financial and legal preferences by the accepting society. Although the position of understanding Islam within the programs of social integration would be more efficient, this calls for the refusal from the formula of multiculturalism, return to the value of social modern based on the universal nature of legal principles and exclusion of religious differences as socially differentiating indicator. "Internal colonization" cannot be overcome, as actions at the political level become the key ones towards Islamic migrants, which makes a lifestyle an "ace" in the fight for equal rights.

Expectations about dominance of "Euroislam"-the system of values and lifestyle similar to the European model of life- contain a simplified idea of the evolution of Islam: Islam in the regions bordering with Europe (The Balkans, Turkey) is considered as a canon. However, one must differentiate between Euroislam as a result of "nationalization" of the Turkish society and Islamic tradition in the Balkans community, where, in the result of Islamisation of the local Slavic population, the lifestyle contained the "archaisms" of paganism and Christianity.

The aspiration to build an image of Islam, which would be acceptable both for migrants and the European community, takes into account the lack of alternatives for co-existence, but ignores the boundaries set by "the ideal form of the current European life": in reality, imaginary free elements are based on the principles of safety and stability (Russia's Ways, 2015). Faith in the correlation between tolerance and unity of society is disputed by the fact that Islam does not need to be a special lifestyle. Developing that idea, one can say that the mass conscience in the European community does not need to be forced with cultural and religious differences.

To provide stability and safety, there is a need for equal access for the citizens to social resources and creation of a common social language, which would be more or less understandable by all members of the society. Encouragement of Islam as a lifestyle creates possibilities for "sovereign" existence, independent from those who are perceived as a different religious community: the Europeans are not only attended with the Christianity principles, but are rather perceived as people who have lost their cultural and religious heritage. This is for a reason that the Islamic diasporas are growing increasingly convinced of their moral and ethical and spiritual superiority over the society which is unable to provide anything to help an individual to comprehend his or her metaphysical (higher) needs.

Posing mainly social claims is determined by the reasonable need to strengthen internal sovereignty, constrain the right of the accepting European community to associate social support and social policy with the requirements to adopt the European model of life and behavior, which seems particularly unconvincing in the context of encouragement of the pluralism of the forms of life.

According to $\mathrm{H}$. Yilmaz, the opinion that the policy of total assimilation has grown out-of-date by sometimes touching on the terminology of the universal citizenship, reveals weakness and reluctance of the European authorities to move in that direction and causes a certain resistance of the Islamic communities to those conversion plans: neither liberal, nor left-wing alternatives for the assimilation policy looks promising and loses supporters even in such a welcome place for multiculturalism as the Netherlands (Yilmaz, 2012). Reference to that circumstance demonstrates a sincere concern of intellectuals about the fact that the concept of multiculturalism, which was supposed to become an alternative for total assimilation, turns out to be helpless in the context of recognition of self-isolation of the Muslims. But if one agrees with the fact that the subject of the religious community is being built, influence of secular norms is pre-determined by clashes with religious dogmas.

Use of the discourse, which claims to be of historic importance, creates the mythology of historical suffering and historical exclusiveness. It is obvious that anti-Islamism is attractive not only for the poor. Elite groups share prejudices of the mass conscience regarding the basic non-integrity of Islam into the reality of the current European society: along with supporting the idea of Euroislam, is stated that history is "separated" from sociology.

That approach is paradoxical, because it is related to the building of the image of "otherness", and in that sense, the actions of "Islamic" migrants are mostly interpreted within studying the Islamic orthodoxy: even if social actions comply with the current instrumental context, adaptation to the Muslim stereotypes is obligatory. T. Radaman, the famous interpreter of Islam in the European world, emphasizes that the Muslims settled in various countries and created various cultures (Ramadan, 2012). He thinks that is it erroneous to perceive Islam as an exclusively conservative lifestyle, which does not permit any changes of norms and rules. On the other hand, Islam as a lifestyle has a traditional nature, because it does not allow an individual to separate from collectivity and cannot justify permissiveness of moral actions.

In the current situation, perception of Islam is mostly determined by the imaginary or real "Islamic" threats, and 
integration of the Muslims into the European community is considered in the categories of counteraction to political and geopolitical risks, which makes it difficult to examine the issue without historical allusions. T. Radaman reminds that the use of the terminology relating to secularization, integration, and assimilation is inevitably identified with the repressions, colonialism, and "destruction" of Islam (Ramadan, 2012). Unlike the European migrants in the USA in the end of XIXthbeginning of the XXth centuries, migrants arriving to Europe do not share faith in the European community as a place of high values.

It would be a simplification to say that we see the syndrome of colonial past at work: references to colonialism mostly take the form of defensive identity. Attitude to the integration is determined, firstly, by the fact that access to basic social goods is not "filtered" by the test for loyalty to the European values; secondly, a stronger reason is the fact that incompatibility between cultural images of the country of origin and cultural images of the accepting party results in controversial policy of transferring cultural development to enthnoreligious communities, which justifies the monopoly of Islamic upbringing. Migrant communities do not produce other cultural images, because acceptance of Islam as a lifestyle excludes co-existence of the religious affiliation and the cultural affinity to the accepting party.

Perhaps, the attitude to social aspects of integration of migrants regarding employment, acquiring of professional skills, career prospects as arising from cultural (religious) differences awakens interest to the explanations of "otherness", while such a phenomenon as "unwillingness to learn the language of the accepting party" can be interpreted through nonconformity between language skills and career prospects. Language test does not play a key role for most of those people who have life chances only for certain ethnic or religious niches. From a culturological perspective, comprehension of social problems creates the situation where the fight against discrimination and racism, which protects the right to cultural and religious uniqueness, from one hand, consolidates the Muslims by the criterion of religious affiliation, and on the other hand, creates the sense of cultural and moral superiority, or contains "light" arguments about social deprivation being determined by affiliation with the Islamic community.

Status of Islam as a lifestyle is strengthening: encouragement of cultural variety through adoptation of initiatives aimed at returning to religious norms lowers social expectations of Islamic migrants. Integration into the Islamic community is becoming a more important aspect of life that social and professional career or achievement of political participation. D. Kandiyoti states that the European multiculturalism poses obstacles on the way of civil laws, because of the conflict with the priority of cultural (religious) authentity, conformity or non-conformity between secular norms and rules and the lifestyle of the community (Yilmaz, 2012). Recognizing it as an extremely complicated issue, the massconscience of the European community expects Islamic migrants to take reciprocal steps.

\section{Conclusions}

The situation of reciprocity is defined so that the right to cultural and religious variety does not break the boundaries of legal freedom: lack of understanding that Islamic lifestyle and religion are inseparable encourages disappointment in the policy of compromises. In the context of the increased risks of Islamisation, fears and prejustices of the masses carry over to the intellectuals that start to create Islam images allowing to state the lack of alternatives for constructive coexistence. The delicacy of the issue consists in the fact that the public discourse demonstrates association and correlation between cultural and sociological aspects.

That must result from the fact that when recognizing religious subjectness, it is difficult to identify socially behavioral parameters and socially symbolical forms produced as a result of perceiving migrants as a marginal group, which is in the borderline state and needs to build its social identity. At the same time, it is recognized that Islam is becoming an identification matrix for migrants, and its paradoxical consequence is an attitude to Islam as a lifestyle within a private space which, in reality, is not separated from the religious subjectness. Thus, the processes of integration/disintegration of migrants as a social "quasigroup", which can be successfully described with sociological tools, are substituted for construction of a religious subjectness, where Islam as a lifestyle is described exclusively through cultural (religious) differences from the accepting party.

\section{Acknowledgement}

This research was financially supported by the grant from the Russian Science Foundation № 15-18-00122 "Institutional practices and value policy in the sphere of harmonization of interethnic relations in the economically developed countries with complex ethnic and cultural structure: comparative analysis and modeling of implementation in the Russian context". 


\section{References}

Blum, A. (2013). Ethnical statistics: Discussion that lost its relevance? In E. Demintseva (Ed.), Racism, xenophobia, discrimination. M.: Novoe literaturnoe obozrenie.

Boender, W. (2012). Teaching Integration in the Netherlands: Islam, Imams and the Secular Government. Perceptions of Islam in Europe. London.

Delantiy, G. (2012). Islam and European Modernityin Historical Perspective: Towards a Cosmopolitan Perspective. Perceptions of Islam in Europe (pp. 13-28). London; N.Y.: I.B. Tauris.

Demintseva, E. (Ed.). (2013). Racism, xenophobia, discrimination. M.: Novoe literaturnoe obozrenie.

Fabbian, J., \& Poli, A. (2013). Debates about building the category "Muslim" in the French public environment. In E. Demintseva (Ed.), Racism, xenophobia, discrimination. M.: Novoe literaturnoe obozrenie.

Gilsenan, M. (2008). Recognizing islam. New York.

Haynes, J. (2012). Islam, pluralism and Politics: What is the Effect of Globalization. Perceptions of Islam in Europe. London; N.Y.: I.B. Tauris.

Kandiyoti, D. (2012). Islam, Gender and Citizenship: Uneasy Encounters in Europe. Perceptions of Islam in Europe. London; N.Y.: I.B. Tauris.

Nuariel, J. (2013). At the origins of racial issue. Racial doctrines and social dominance. In E. Demintseva (Ed.), Racism, xenophobia, discrimination (p. 120). M.: Novoe literaturnoe obozrenie.

Pugacheva, M. G., \& Philippov, A. F. (Eds.). (2015). Russia's ways. Alternatives of social development (p. 15). Moscow: NLO.

Ramadan, T. (2012). The Arab awakening. London: Oxford University Press.

Said, W. E. (2003.) Orientalism London (p. 206). Penguin Books.

Yilmaz, H. (Ed.). (2012). Perceptions of Islam in Europe. London; N.Y.: I.B. Tauris. 